\title{
Cell Cycle and Glomerular Disease: A Minireview
}

\author{
Caroline B. Marshall Stuart J. Shankland \\ Division of Nephrology, Department of Medicine, University of Washington, Seattle, Wash., USA
}

\section{Key Words \\ Cell cycle $\cdot$ Kidney $\cdot$ Glomerulus $\cdot$ Proliferation . \\ Podocyte $\cdot$ Mesangial cell $\cdot$ Progressive \\ glomerulosclerosis $\cdot$ Hypertrophy $\cdot$ Apoptosis}

\begin{abstract}
Globally, glomerular diseases are a leading cause of chronic and end-stage renal disease. In the mature glomerulus, under normal conditions, glomerular cells have a low turnover rate. However, in disease, a variety of pathophysiological stimuli can lead to disturbances in glomerular cell biology, including toxins, immune-mediated stresses, metabolic derangements, drugs, infections, hemodynamic changes, growth factors, and cytokines. Not only does the form of injury govern the histologic and clinical manifestations of disease, but also the nature of the response to injury. This response to injury is largely cell-type specific, and the glomerulus represents a rare microcosm of the larger organism in which one can study the cellular responses of three very distinct cell types: mesangial cells, visceral epithelial cells or podocytes, and endothelial cells. These cells can undergo several cell fates in response to injury, including proliferation, de-differentiation, hypertrophy, senescence, apoptosis, or necrosis. The regulation of these responses occurs at the level of the cell cycle, coordi-
\end{abstract}

nated by positive regulators, cyclins and cyclin-dependent kinases, and negative regulators, cyclin-dependent kinase inhibitors. There is now a large body of literature confirming the importance of cell cycle regulatory proteins in the glomerular cellular response to injury. The recent advances in cell cycle biology in diseases of the mesangial cell and the podocyte are the focus of this minireview.

Copyright $(2006$ S. Karger AG, Basel

\section{Introduction}

Glomerular diseases are a leading cause of chronic and end-stage kidney failure worldwide. Diseases of the glomerulus have been divided clinically into two primary groups based on the presenting clinico-pathologic syndrome: nephritic versus nephrotic. An alternate classification, preferred by the authors, characterizes glomerular diseases according to the principal cell type injured. Glomerular diseases are considered consequences of injury primarily to the three cell types existing within the glomerular tuft: mesangial cells, podocytes (visceral epithelial cells), and endothelial cells. In addition to cell type, the form of injury determines the response to injury, ultimately governing the histologic and clinical manifestations of disease.

\section{KARGER}

(c) 2006 S. Karger AG, Basel

Fax +4161306 1234

E-Mailkarger@karger.ch

www.karger.com
Stuart J. Shankland, MD

Head, Division of Nephrology, University of Washington

1959 NE Pacific Street, Box 356521

Seattle, WA 98195 (USA)

Tel. +1 206 5432346, Fax +1 206 6858661, E-Mail stuartjs@u.washington.edu 
Table 1. Cell cycle regulatory proteins in glomerular disease

\begin{tabular}{|c|c|c|c|c|}
\hline Experimental model & Cell type & Cyclin & $\mathrm{CDK}$ & CDK Inhibitor \\
\hline \multicolumn{5}{|l|}{ Proliferation } \\
\hline In vitro exposure to mitogens (PDGF, BFGF) & $\mathrm{MC}$ & $\uparrow \mathrm{D} 1, \leftrightarrow \mathrm{E}, \uparrow \mathrm{A}$ & $\uparrow \mathrm{CDK} 4, \uparrow \mathrm{CDK} 2$ & $\uparrow \mathrm{p} 21, \downarrow \mathrm{p} 27, \leftrightarrow \mathrm{p} 57$ \\
\hline Thy 1 , early phase & $\mathrm{MC}$ & $\uparrow \mathrm{D} 1, \uparrow \uparrow \uparrow \mathrm{A}$ & $\uparrow \mathrm{CDK} 4, \uparrow \uparrow \uparrow \mathrm{CDK} 2$ & $\uparrow \mathrm{p} 15, \uparrow \mathrm{p} 21, \downarrow \downarrow \downarrow \mathrm{p} 27$ \\
\hline Remnant kidney & $\mathrm{MC}$ & $\uparrow \mathrm{E}$ & $\uparrow \mathrm{CDK} 2$ & \\
\hline Anti-glomerular antibody & Podocyte & $\uparrow \mathrm{A}$ & $\uparrow \mathrm{CDK} 2, \downarrow \mathrm{CDK} 5$ & \\
\hline PHN & Podocyte & $\uparrow \mathrm{A}$ & $\uparrow \mathrm{CDK} 2$ & $\begin{array}{l}\uparrow \uparrow \uparrow \mathrm{p} 21, \uparrow \uparrow \uparrow \mathrm{p} 27 \\
\leftrightarrow \mathrm{p} 15, \leftrightarrow \mathrm{p} 57\end{array}$ \\
\hline Collapsing glomerulopathy & Podocyte & $\uparrow \mathrm{A}, \downarrow \mathrm{D} 1$ & $\downarrow$ CDK5 & 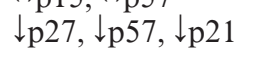 \\
\hline \multicolumn{5}{|l|}{ Hypertrophy } \\
\hline In vitro exposure to high glucose & $\mathrm{MC}$ & $\uparrow \mathrm{D} 1$ & $\uparrow \mathrm{CDK} 4, \leftrightarrow \mathrm{CDK} 2$ & $\uparrow \mathrm{p} 21, \uparrow \mathrm{p} 27$ \\
\hline In vitro exposure to TGF- $\beta$ & $\mathrm{MC}$ & & & $\uparrow \mathrm{p} 21, \uparrow \mathrm{p} 27$ \\
\hline In vitro exposure to CTGF & $\mathrm{MC}$ & & & $\uparrow \mathrm{p} 15, \uparrow \mathrm{p} 21, \uparrow \mathrm{p} 27$ \\
\hline STZ-diabetes, BBdp rat (type 1 ) & $\mathrm{MC}$ & $\leftrightarrow \mathrm{E}, \leftrightarrow \mathrm{A}$ & $\leftrightarrow \mathrm{CDK} 2$ & $\uparrow \uparrow \uparrow \mathrm{p} 21, \uparrow \mathrm{p} 27$ \\
\hline$d b / d b$ rat, Zucker rat (type 2) & $\mathrm{MC}$ & & $\leftrightarrow \mathrm{CDK} 2$ & $\uparrow \uparrow \uparrow \mathrm{p} 27$ \\
\hline Mechanical stretch & Podocyte & $\downarrow \mathrm{D} 1, \downarrow \mathrm{A}, \downarrow \mathrm{B} 1$ & $\downarrow \mathrm{Cdc} 2$ & $\uparrow \mathrm{p} 21, \uparrow \mathrm{p} 27, \uparrow \mathrm{p} 57$ \\
\hline ZDF-fa/fa rat (type 2) & Podocyte & & & $\uparrow \mathrm{p} 27, \uparrow \mathrm{p} 21, \leftrightarrow \mathrm{p} 57$ \\
\hline \multicolumn{5}{|l|}{ Apoptosis } \\
\hline PHN & Podocyte & $\uparrow \mathrm{A}$ & $\uparrow \mathrm{CDK} 2$ & $\uparrow \mathrm{p} 21, \downarrow \mathrm{p} 57$ \\
\hline Anti-glomerular antibody & Podocyte & $\uparrow \mathrm{A}$ & $\uparrow \mathrm{CDK} 2$ & $\uparrow \mathrm{p} 21, \uparrow \mathrm{p} 27, \downarrow \mathrm{p} 57$ \\
\hline Mechanical stretch & Podocyte & $\uparrow \mathrm{D} 1, \uparrow \mathrm{A}, \uparrow \mathrm{B} 1$ & $\uparrow \mathrm{Cdc} 2$ & $\uparrow \mathrm{p} 21, \uparrow \mathrm{p} 27, \uparrow \mathrm{p} 57$ \\
\hline Thy 1 , resolution phase & $\mathrm{MC}$ & $\uparrow \mathrm{E}, \uparrow \mathrm{A}$ & $\uparrow \mathrm{CDK} 2$ & $\downarrow_{\mathrm{p} 27}$ \\
\hline
\end{tabular}

$\mathrm{PDGF}=$ Platelet-derived growth factor; $\mathrm{BFGF}=$ basic fibroblast growth factor; $\mathrm{MC}=$ mesangial cell; $\mathrm{PHN}=$ passive Heymann nephritis; STZ = streptozotocin; TGF- $\beta=$ transforming growth factor $\beta$; CTGF = connective tissue growth factor; Thy $1=$ Thy 1 mesangial proliferative glomerulonephritis.

$\uparrow=$ Mild increase; $\uparrow \uparrow \uparrow=$ marked increase; $\leftrightarrow=$ no change; $\downarrow=$ mild decrease; $\downarrow \downarrow \downarrow=$ marked decrease.

In response to injury, glomerular cells may undergo several cell fates, including proliferation, de-differentiation, hypertrophy, senescence, apoptosis, or necrosis. However, common to these outcomes is their ultimate regulation at the level of the cell cycle by specific cell cycle regulatory proteins (table 1). Although first described and identified for their roles as coordinators of cell cycle progression and proliferation, recent research has characterized a more extensive involvement of cell cycle regulatory proteins in other fundamental biologic processes, including development, differentiation, hypertrophy, and apoptosis.

Glomerular cell cycle control is particularly fascinating given the divergent responses of the resident cell types to injury. Due to space limitation, the authors are unable to provide a detailed background on cell cycle regulatory proteins, and the reader is directed to suggested references $[1,2]$ and to figure 1 . Briefly, specific cell cycle regulatory proteins govern each phase of the cell cycle. Progression, from the quiescent phase $\left(\mathrm{G}_{0}\right)$ through DNA synthesis ( $\mathrm{S}$ phase) and mitosis (M phase), requires the activation of cyclin-dependent kinases (CDK) by specific cyclins. Two families of CDK-inhibitors bind to and inhibit cyclin-CDK complexes, thereby preventing cell cycle progression. Recent advances in cell cycle biology in diseases of the mesangial cell and the podocyte will be reviewed.

\section{Mesangial Cell's Response to Injury}

The mesangial cell's roles in the glomerular capillary include (i) structural support of the capillary tuft, (ii) glomerular hemodynamic modulation, and (iii) phagocytosis of macromolecules and immune complexes. An array of glomerular diseases is distinguished by mesangial cell injury, including IgA nephropathy, lupus nephritis, deposition diseases such as amyloidosis, membranoproliferative glomerulonephritis, and diabetic nephropathy. Typical mesangial cell fates that are regulated by cell cycle 


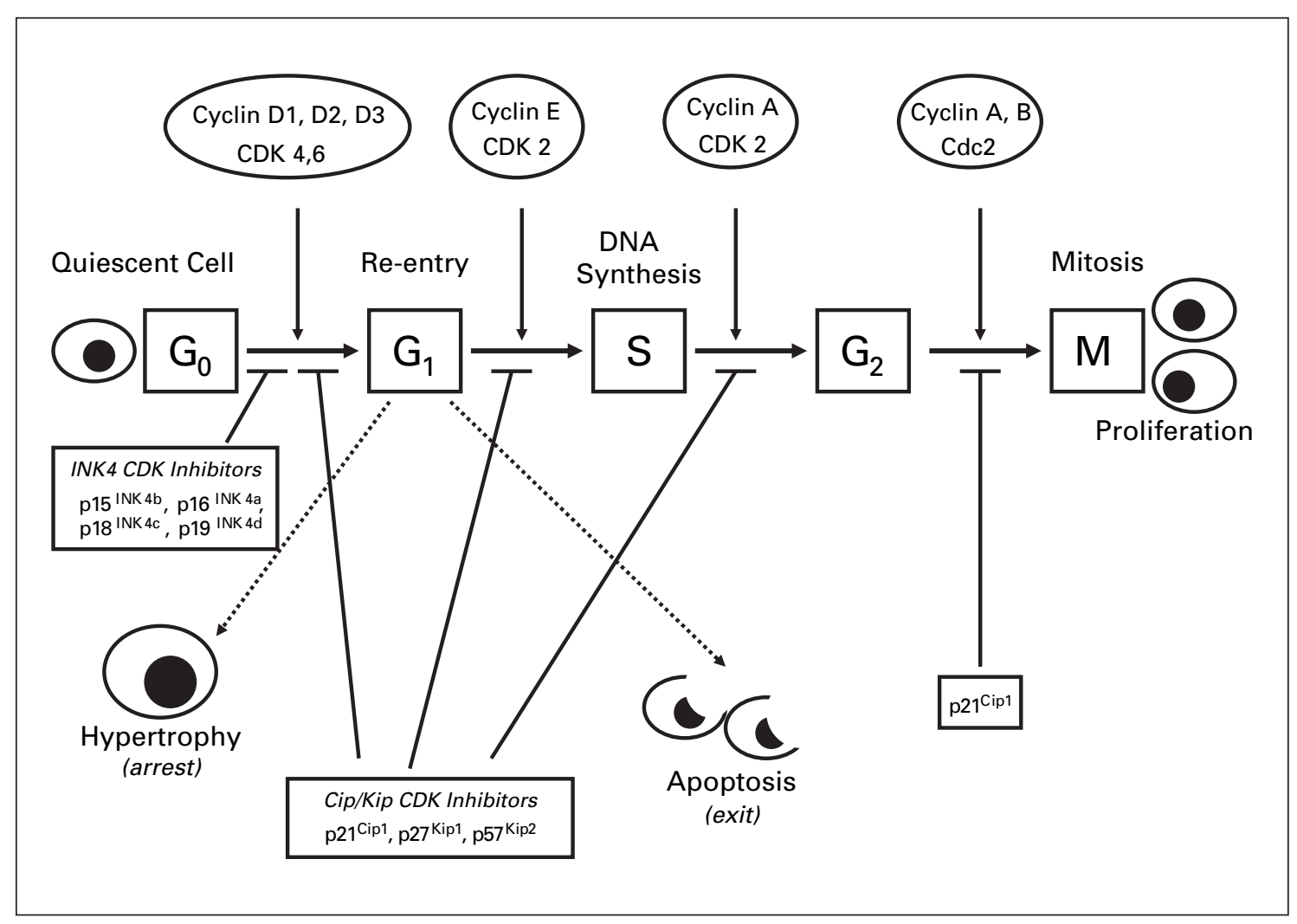

Fig. 1. The cell cycle. With mitogenic stimuli, quiescent cells in $\mathrm{G}_{0}$ re-enter the cell cycle at early $G_{1}$, followed by $S$ phase, during which DNA synthesis occurs. During $\mathrm{G}_{2}$ phase, cell growth continues and proteins are synthesized in preparation for entry into the $\mathrm{M}$ phase, where mitosis occurs. The transition from late $G_{1}$ into the $S$ phase determines the cell's growth characteristics. $G_{1}$ arrest results in hypertrophy; $G_{1}$ exit is associated with apoptosis; and $G_{1} / S$ transition results in DNA synthesis and proliferation. Cyclin-dependent kinases (CDKs) and cyclins act as positive regulators. CDKs, a family of serine-threonine kinases, are constitutively expressed throughout the cell cycle. Each CDK complex contains one of many acti- vating subunits, cyclins, whose levels fluctuate throughout the cell cycle. The cyclin-CDK complexes are regulated by multiple phosphorylation and dephosphorylation events and by several subunits named CDK-inhibitors. Two classes of CDK-inhibitors have been identified: the INK4 family and the Cip/Kip family. Individual CDK-inhibitors are named according to their molecular weights. For simplicity, the Cip/Kip family is represented as strictly inhibitory. However, this family of CDK-inhibitors actually plays dual roles as both activators and inhibitors at different stages of the cell cycle $[1,2]$. proteins include proliferation, apoptosis, and hypertrophy. For a summary of the mesangial cell's response to injury, see figure 2.

\section{Mesangial Cell Proliferation}

Mesangial cell proliferation underlies, and likely causes, an accumulation in extracellular proteins and subsequent glomerular scarring [3]. Thus, understanding the mechanisms governing proliferation is critical. Mesangial proliferative glomerulonephritis (Thyl model), induced in rats by an antibody directed against the mesangial cell Thy 1 antigen, offers a useful model to examine the regulation and consequences of mesangial cell proliferation
[4]. In this model, the initial complement-dependent mesangiolysis is followed by a phase of marked mesangial proliferation, a response correlated with increases in cyclin D1, cyclin A, CDK4, and CDK2 [5]. The level and activity of CDK2, normally present in low abundance in quiescent mesangial cells, are also augmented in other experimental models characterized by mesangial proliferation, including the non-immune-mediated remnant kidney model, and in cultured mesangial cells exposed to mitogens [5].

To define better the biological significance of increased CDKs, the ATP binding site competitor roscovitine, a potent inhibitor of $\mathrm{Cdc} 2, \mathrm{CDK} 2$, and $\mathrm{CDK} 5$, was used to 
Fig. 2. Mesangial cell's response to injury. In response to injury, the mesangial cell can undergo several cell fates, including apoptosis, proliferation, and hypertrophy.

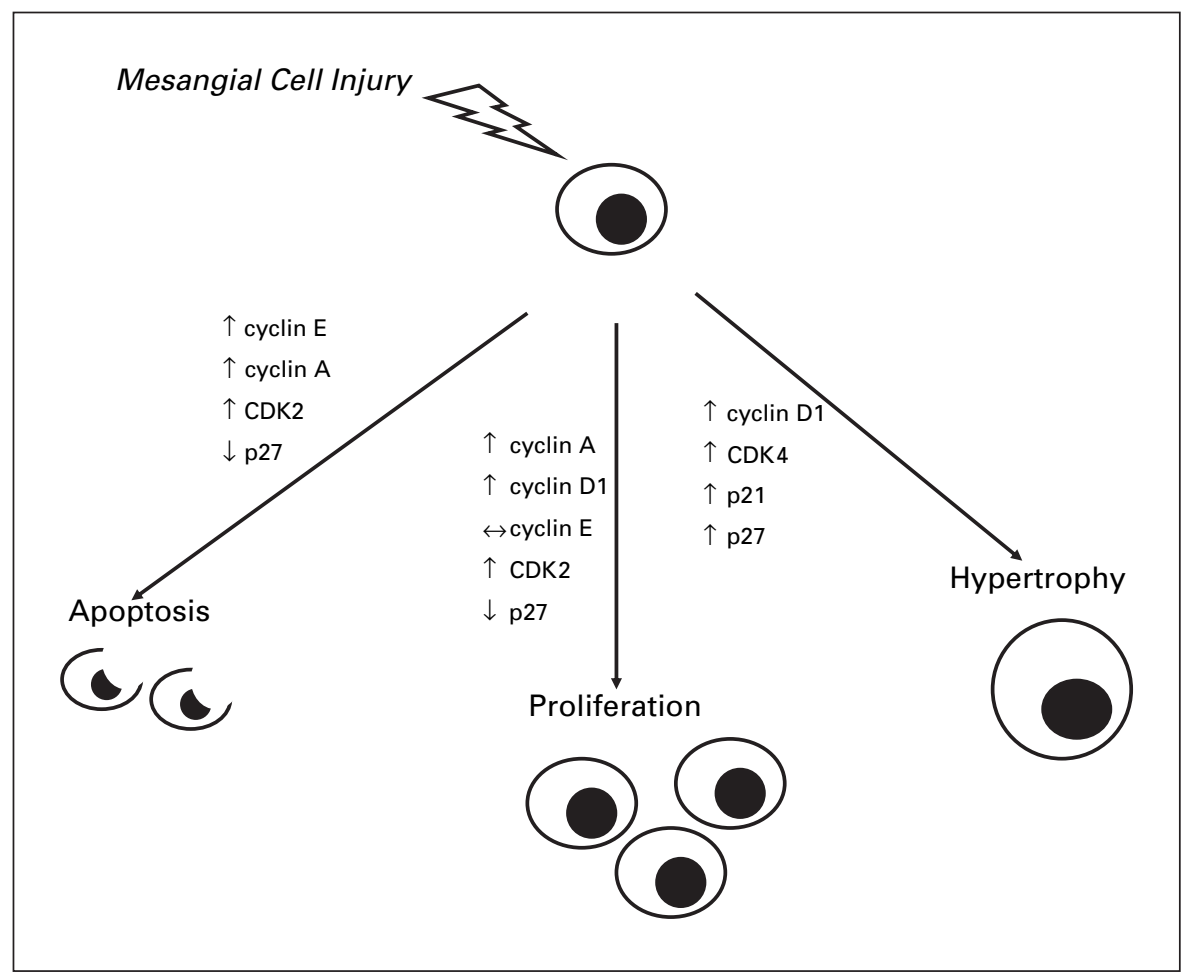

inhibit CDK activity in experimental mesangial proliferative glomerulonephritis. Roscovitine, when administered either immediately after disease induction (i.e., prior to the onset of mesangial cell proliferation) or once mesangial proliferation was already established, significantly reduced mesangial cell proliferation [6]. Moreover, reduction in proliferation was associated with reduced glomerular extracellular matrix proteins (collagen IV, laminin, fibronectin), and improved renal function. Subsequent studies have shown that roscovitine also ameliorated immune-mediated glomerulonephritis induced by the administration of an anti-glomerular antibody in mice. These findings suggest that amplification or overexpression of cell cycle kinases may play a critical role in inflammatory glomerulonephritis. These cell cycle kinases may be potential therapeutic targets in diseases characterized by glomerular cell proliferation. However, given the promiscuous targeting of kinases by roscovitine, including potentially non-cell cycle kinases and kinases in unaffected and normal cells, significant toxicity may result. To reduce potential toxicities, there are new generations of CDK-inhibiting drugs in development, specifically for treatment of malignancies, which may be applicable in future therapy for glomerular proliferative diseases.
A role for specific CDK-inhibitors has also been shown in mesangial cells $[5,7]$. In quiescent mesangial cells, $\mathrm{p} 27^{\mathrm{Kip} 1}$ is expressed constitutively, whereas $\mathrm{p} 21^{\mathrm{Cip} 1}$ and $\mathrm{p} 57^{\mathrm{Kip} 2}$ are barely detected. Immune-mediated injury in experimental mesangial proliferative glomerulonephritis leads to a striking decrease in $\mathrm{p} 27^{\mathrm{Kip} 1}$ levels. Yet, during the resolution phase of disease, there is de novo synthesis of $\mathrm{p} 21^{\mathrm{Cip} 1}$, concomitant with a decrease in proliferation. To explore further the role of $\mathrm{p} 27^{\mathrm{Kip} 1}$, experimental glomerulonephritis was induced in $\mathrm{p} 27^{\mathrm{Kip} 1}-/-$ mice. The onset of glomerular cell proliferation occurred earlier, and the magnitude of proliferation was greater, in nephritic p $27^{\text {Kip } 1-/-~ m i c e ~ c o m p a r e d ~ w i t h ~ n e p h r i t i c ~ p 2 ~} 7^{\mathrm{Kip} 1}+/+$ mice. Increased proliferation was coupled with extracellular matrix expansion and deterioration in renal function [8]. Taken together, these studies show that $\mathrm{p} 27^{\mathrm{Kip} 1}$ regulates the onset and magnitude of mesangial cell proliferation and, therefore, matrix accumulation and subsequent decline in renal function.

\section{Mesangial Cell Apoptosis}

Studies have shown that apoptosis is an essential mechanism in normalizing mesangial cell number in the reparative phase of injury. Nevertheless, the cellular pathways linking these opposing responses, proliferation and 
apoptosis, remain poorly defined. Still, cell cycle proteins are predicted to have a crucial role in both processes, as many cells undergoing apoptosis have re-entered the cell cycle before exiting by apoptosis.

The resolution phase of mesangial proliferative glomerulonephritis is typified by mesangial cell apoptosis, a process that peaks when the levels of $\mathrm{p} 27^{\mathrm{Kip} 1}$ are at their lowest [5]. Furthermore, in both glomerulonephritis and ureteral obstruction, there is an increase in glomerular cell proliferation following injury, which is associated with a marked increase in glomerular cell apoptosis in $\mathrm{p} 27^{\mathrm{Kip} 1}-/$ - mice when compared with wild-type controls [8]. Moreover, apoptosis was also increased in p2 $7^{\mathrm{Kip} 1}-/-$ mesangial cells in culture after exposure to apoptotic triggers, with the reconstitution of $\mathrm{p} 27^{\mathrm{Kip} 1} \mathrm{lev}$ els by transfection rescuing the cells from apoptosis [9]. In addition, in rat mesangial cells, apoptosis was increased after treatment with anti-p2 $7^{\mathrm{Kip} 1}$ antisense oligonucleotides [9]. Taken together, these results confirm the importance of $\mathrm{p} 27^{\mathrm{Kip} 1}$ in both the regulation of proliferation and the protection from apoptosis. Thus, the CDK-inhibitor $\mathrm{p} 27^{\mathrm{Kip} 1}$ has a critical role in governing overall mesangial cell number.

\section{Mesangial Cell Hypertrophy}

A hallmark of diabetic nephropathy is mesangial cell hypertrophy. On entry into $G_{1}$, cells normally undergo a physiologic increase in protein synthesis before $S$ phase DNA synthesis. In hypertrophic cells, an increase in protein content is not matched by a concurrent increase in DNA. Consequently, one mechanism underlying cellular hypertrophy is cell cycle arrest at the $\mathrm{G}_{1} / \mathrm{S}$ checkpoint, leading to increased protein to DNA ratio (the biochemical definition of hypertrophy). Studies have shown that glomerular hypertrophy predicts, and likely causes, increased extracellular matrix proteins.

In vitro, upon exposure to high glucose, mesangial cells enter the cell cycle and exhibit a biphasic growth response [10]. The initial proliferative phase is followed by $\mathrm{G}_{1}$ arrest, with progressive hypertrophy. Hyperglycemia increases the expression of cyclin D1 and the activation of CDK4, evidence of cell cycle entry [11]. Recent studies have shown a role for CDK-inhibitors in mesangial cell hypertrophy. Hyperglycemia increases the levels of both $\mathrm{p} 21^{\mathrm{Cip} 1}$ and $\mathrm{p} 27^{\mathrm{Kip} 1}$ in cultured mesangial cells, and antisense oligonucleotides to $\mathrm{p} 21^{\mathrm{Cip} 1}$ or $\mathrm{p} 27^{\mathrm{Kip} 1}$ reduce the hypertrophic effects of hyperglycemia. Fan and Weiss [12] recently showed that $\mathrm{p} 21^{\mathrm{Cip} 1}$ antisense oligonucleotide leads to a dose-dependent reduction of hyperglycemia-induced hypertrophy in human mesangial cells. Fur- thermore, in $\mathrm{p} 21^{\mathrm{Cip} 1}-/-$ and $\mathrm{p} 27^{\mathrm{Kip} 1}-/-$ mesangial cells in culture, hypertrophy is not induced by hyperglycemia. Providing further support for the role of $\mathrm{p} 27^{\mathrm{Kip} 1}$ in hyperglycemia-induced hypertrophy, the reconstitution of p $27^{\mathrm{Kip} 1}$ by transfection in $\mathrm{p} 27^{\mathrm{Kip} 1}-/-$ mesangial cells restores the hypertrophic phenotype [13, 14]. More recently, studies showed that both $\mathrm{p} 21^{\mathrm{Cip} 1}$ and $\mathrm{p} 27^{\mathrm{Kip} 1}$ are required for maximal mesangial cell hypertrophy induced by transforming growth factor (TGF)- $\beta$ [12]. Taken together, following an initial entry into the cell cycle upon exposure to high glucose, the subsequent increase in CDKinhibitors leads to hypertrophy by arresting the cell cycle before $\mathrm{S}$ phase, thereby preventing the DNA replication that typically follows the increase in protein content.

These findings have been corroborated in experimental models of type 1 (streptozotocin-induced mouse model) [15] and type 2 ( $d b / d b$ mouse) diabetic nephropathy. Diabetic p2 $1^{\text {Cip } 1-/-~ m i c e ~ a r e ~ p r o t e c t e d ~ f r o m ~ g l o m e r u l a r ~}$ hypertrophy and development of progressive renal failure

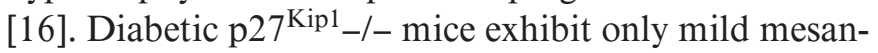
gial expansion without glomerular hypertrophy, despite an increase in glomerular TGF- $\beta$ [17]. Taken together, the cell culture and experimental models show that $\mathrm{p} 21^{\mathrm{Cip} 1}$ and $\mathrm{p} 27^{\mathrm{Kip} 1}$ play a critical role in mediating diabetes-associated glomerular hypertrophy and the consequential increase in matrix proteins, associated with the deterioration in renal function.

\section{The Podocyte's Response to Injury}

The podocyte is a highly specialized and terminally differentiated epithelial cell overlying the outer aspect of the glomerular basement membrane, whose complex cytoarchitecture determines its elaborate function as a critical component of the glomerular filtration barrier. In this capacity, podocytes function to prevent urinary protein leakage, maintain the integrity of the underlying glomerular capillary loops, oppose intracapillary hydrostatic pressure, and synthesize the glomerular basement membrane [18]. Thus, the mechanisms governing podocyte differentiation, and therefore proliferation, are essential to the normal function of this cell. Podocyte response to injury includes effacement, detachment, and glomerulosclerosis. Figure 3 summarizes the podocyte's response to injury at the level of the cell cycle.

\section{Podocyte Proliferation and Differentiation}

Due to its highly differentiated state, analogous to the neuron, the podocyte typically does not proliferate in 
Fig. 3. Podocyte's response to injury. In response to injury, the normally quiescent and highly differentiated podocyte can undergo several cell fates, depending on the type of injury. De-differentiation, due to a decrease in CDK-inhibitors, permits cell cycle re-entry, and proliferation occurs when cyclins and CDKs are activated. In contrast, most forms of injury lead to a decrease in podocyte number (podocytopenia) because of apoptosis, hypertrophy, lack of proliferation, or presence of DNA damage. Levels of cyclins, CDKs, CDK-inhibitors, or other checkpoint proteins may determine which of these fates podocytes undergo.

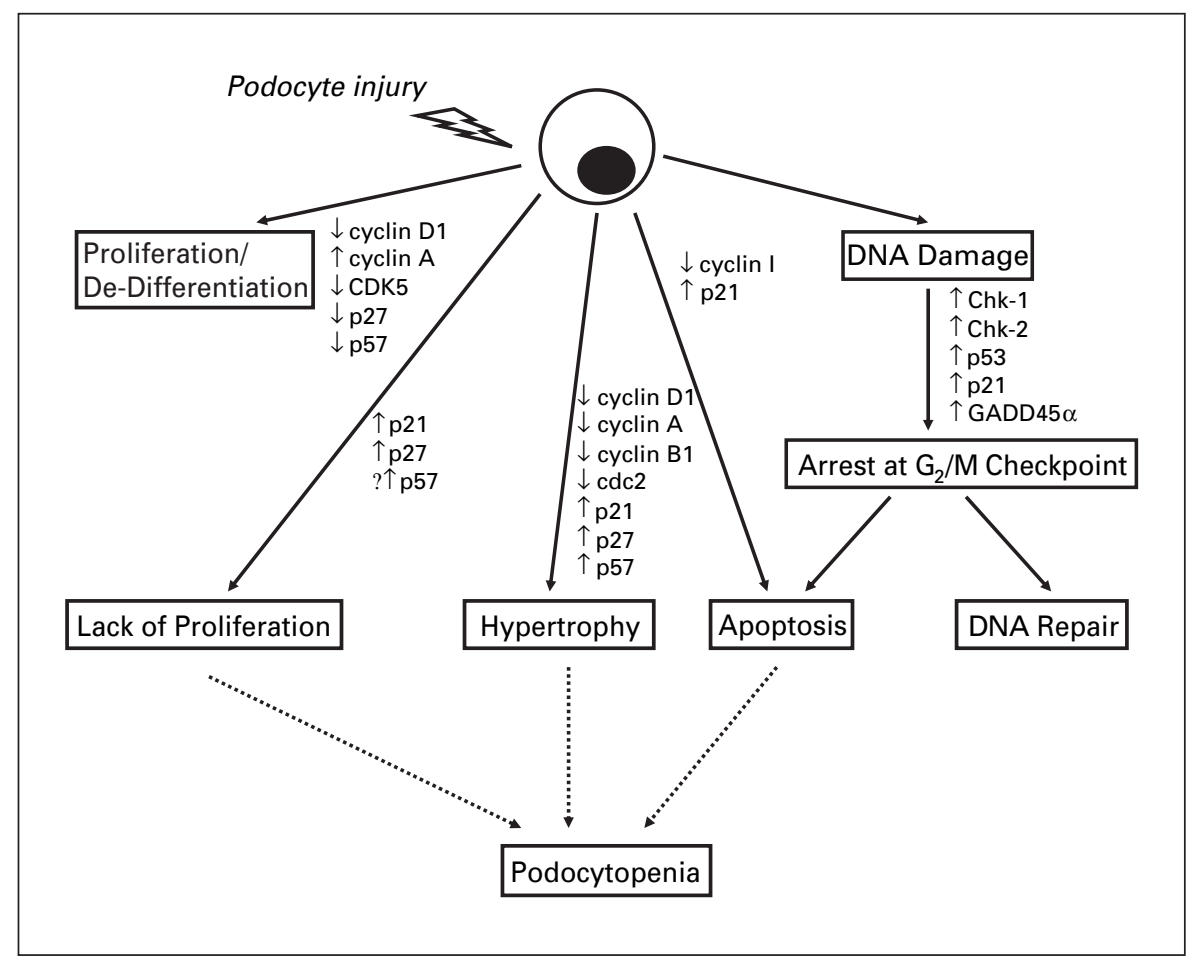

vivo. The tight regulatory control of cell cycle quiescence in podocytes, sustained by a strong and specific upregulation of CDK-inhibitors, may guarantee their highly specialized structure and function and is a prerequisite for terminal differentiation. In sharp contrast to the proliferative capacity of neighboring mesangial and endothelial cells in response to injury, as podocytes detach, apoptose, and necrose following injury, there is a reduction in podocyte number, associated with a relative lack of proliferation. The consequential podocyte loss results in areas of denuded basement membrane, ultimately leading to proteinuria, the development of scarring, known as focal glomerulosclerosis, and progressive deterioration in kidney function.

During glomerulogenesis, immature podocyte precursor cells proliferate. In the S-shaped body stage of glomerulogenesis, presumptive podocytes express proliferative tissue markers, including proliferating cell nuclear antigen (PCNA) and Ki-67, together with cyclins A and B1. In both mouse and human glomerulogenesis, immunostaining for $\mathrm{p} 27^{\mathrm{Kip} 1}$ and $\mathrm{p} 57^{\mathrm{Kip} 2}$ is absent at this early stage. With transition to the capillary loop state, a fundamental phenotypic switch occurs with cessation of mitotic activity, reorganization of the cytoskeleton, expression of podocyte maturity markers (including synaptopo- din and glomerular epithelial protein-1), and development of foot-process interdigitation. In parallel to these changes, there is a decrease in levels of cell cycle promoters (cyclins and CDKs), and a reciprocal upregulation of $\mathrm{p} 27^{\mathrm{Kip} 1}$ and $\mathrm{p} 57^{\mathrm{Kip} 2}$. These events coincide with the cessation of proliferation, as podocytes become terminally differentiated and quiescent - necessary requirements for normal function [7, 19]. However, null mice have shown that $\mathrm{p} 21^{\mathrm{Cip} 1}, \mathrm{p} 27^{\mathrm{Kip} 1}$, and $\mathrm{p} 57^{\mathrm{Kip} 2}$ alone are not essential for glomerular development.

In the mature glomerulus, podocytes do not readily proliferate under normal conditions or in response to a wide variety of injuries. The podocyte's inability to proliferate in many diseases is most likely the consequence of robust expression, or even upregulation, of the CDKinhibitors $\mathrm{p} 21^{\mathrm{Cip} 1}, \mathrm{p} 27^{\mathrm{Kip} 1}$, and $\mathrm{p} 57^{\mathrm{Kip} 2}$ with disease progression. However, in idiopathic collapsing glomerulopathy and HIV-associated nephropathy, dysregulation of the differentiated phenotype and proliferation can occur [18]. In collapsing glomerulopathy, Barisoni et al. [20] showed that podocyte number was increased in affected tissue and that, accompanying this proliferation, there was associated de-differentiation (loss of maturity markers, including synaptopodin) and phenotypic dysregulation (loss of Wilm's tumor protein). In proliferating podo- 
cytes overlying areas of collapse, $\mathrm{p} 57^{\mathrm{Kip} 2}$ and $\mathrm{p} 27^{\mathrm{Kip} 1}$ are reduced and cyclin A increased. This form of non-reparative proliferation is characterized by the podocyte's escape from cell cycle blockade, leading to a disruption of glomerular architecture followed by rapidly declining renal function.

Further support of a critical role for $\mathrm{p} 21^{\mathrm{Cip} 1}$ and $\mathrm{p} 27^{\mathrm{Kip} 1}$ in limiting the proliferative response of podocytes in many disease processes comes from studies in $\mathrm{p} 21^{\mathrm{Cip} 1}-/$ and $\mathrm{p} 27^{\mathrm{Kip} 1}-/-$ mice. With the administration of an antiglomerular antibody, podocyte de-differentiation and proliferation increased in $\mathrm{p} 21^{\mathrm{Cip} 1}-/-$ and $\mathrm{p} 27^{\mathrm{Kip} 1}-/-$ mice compared with wild-type mice [21]. Podocyte proliferation was accompanied by extracellular matrix accumulation with associated decline in renal function. Inhibiting podocyte proliferation with the CDK-inhibitor roscovitine leads to reduced glomerulosclerosis and improved renal function. Taken together, proliferation is detrimental to the normal biological function of podocytes, and the decision to proliferate is likely controlled by a reduction in CDK inhibition.

\section{Podocyte DNA Damage and Lack of Proliferation}

Abnormalities in DNA Synthesis

The passive Heymann nephritis (PHN) model, induced by the administration of an antibody reactive against the rat podocyte Fx1A antigen, has many similarities to human membranous nephropathy. In both diseases, complement activation, with the assembly of the terminal complement components to form C5b-9, the membrane attack complex, is the principal mediator of glomerular injury. Nucleated cells are relatively resistant to C5b-9 attack and may actually become activated by it, leading to release of inflammatory mediators, calcium, oxidants, growth factors, matrix components, and proteases. C5b-9 is also central to mesangial cell injury in mesangial proliferative glomerulonephritis. However, in mesangial cells, C5b-9 attack leads to DNA synthesis and a marked proliferative response [22]. In contrast, although podocytes also re-engage the cell cycle following C5b-9 injury, as demonstrated by an increase in cyclins and CDKs required for proliferation (cyclin A and CDK2 protein levels increase), they undergo limited DNA synthesis, and podocyte number typically remains constant, and even decreases with time. These findings are consistent with a defect in DNA synthesis (S phase of cell cycle). Indeed, the levels of $\mathrm{p} 21^{\mathrm{Cip} 1}$ and $\mathrm{p} 27^{\mathrm{Kip} 1}$ increase specifically in podocytes after induction of PHN, supporting the notion that increased CDK-inhibitors prevent podocyte cell cycle progression, and therefore, DNA synthesis.

\section{Abnormalities in Mitosis}

An important question is whether abnormalities in podocyte mitosis can account for additional or alternate mechanisms for post-injury limitation of proliferation. Recent studies in PHN rats showed that podocytes do increase their levels of cyclin B-Cdc2, the cell cycle proteins required for mitosis. However, mitosis is infrequent. This suggests an abnormality in the $\mathrm{G}_{2} / \mathrm{M}$ checkpoint, which precedes mitosis. Indeed, sublytic C5b-9 injury causes DNA damage in podocytes in vitro and in vivo, accompanied by a delay or inhibition in entering mitosis, i.e., $\mathrm{G}_{2} / \mathrm{M}$ phase arrest. In contrast, upon exposure to sublytic C5b-9, DNA damage is not seen in mesangial cells. In podocytes, DNA damage is associated with a marked increase in cell cycle checkpoint proteins checkpoint kinase 1 (Chk-1), checkpoint kinase 2 (Chk-2), tumor suppressor $\mathrm{p} 53$, and $\mathrm{p} 21^{\mathrm{Cip} 1}$, which converge on and inhibit the $\mathrm{G}_{2} / \mathrm{M}$ phase checkpoint, thus limiting mitosis [23]. These observations support the hypothesis that $\mathrm{p} 21^{\text {Cip } 1}$, a downstream effector of p53 in the DNA damage checkpoint pathway, plays a critical role in limiting proliferation.

When $\mathrm{p} 21^{\mathrm{Cip} 1}-/-$ mouse podocytes were exposed to sublytic C5b-9, at time points beyond $6 \mathrm{~h}$, there were increased levels of DNA damage compared to $\mathrm{p} 21^{\mathrm{Cip} 1}+/+$ podocytes. This greater degree of DNA damage in p2 $1^{\text {Cip1 } 1 /-~ p o d o c y t e s ~ w a s ~ n o t ~ a c c o m p a n i e d ~ b y ~ a n ~ i n-~}$ crease of DNA damage checkpoint proteins (including Chk-1, Chk-2, p53, and growth arrest and DNA damage inducible gene (GADD45 $\alpha$ ) ) as was seen in the wild-type podocytes [unpubl. data] (for an overview of $\mathrm{G}_{2} / \mathrm{M}$ cell cycle checkpoints, see figure 4) [24]. Taken together, p $21^{\text {Cip } 1}$ likely plays a critical role in the podocyte's cell cycle arrest in response to DNA damage and in the regulation of DNA damage response effectors.

DNA damage may also account for the inability of podocytes to proliferate in response to injury in other disease models. In the puromycin aminonucleoside nephropathy animal model of minimal-change disease progressing to focal segmental glomerulosclerosis, DNA damage has been documented and data supports that this is mediated by reactive oxygen species. Puromycin aminonucleoside also induced DNA damage in cultured mouse podocytes, accompanied by an upregulation of p2 $1^{\text {Cip1 }}$, GADD45 $\alpha$, p53, Chk-1, Chk-2, and the repair enzymes DNA polymerase- $\beta$ and AP-endonuclease [unpubl. data]. Therefore, in both immune- and non-immunemediated podocyte injury, in vitro and in vivo, the podocyte's lack of proliferation may be due to injury-induced DNA damage with upregulation of cell cycle checkpoint proteins, including $\mathrm{p} 21^{\mathrm{Cip} 1}$, leading to $\mathrm{G}_{2} / \mathrm{M}$ phase arrest. 
Fig. 4. Cell cycle checkpoints and the limitation of podocyte mitosis. Cell cycle checkpoint proteins, enforcing the orderly execution of the cell cycle, are response elements that operate to maintain the fidelity of DNA replication, repair, and, ultimately, cell division. The proteins that act as sensors of damaged DNA, not yet fully characterized, serve to activate signaling pathways that lead not only to cell cycle arrest, but also to activation of DNA repair or other cell fate pathways. The immediate targets of the sensor proteins are two related protein kinases, designated ATM (mutated in ataxia telangiectasia) and ATR (ATM and Rad3-related), which are activated in response to DNA damage. Two checkpoint kinases, Chk-1 and Chk-2, link ATM and ATR to downstream effectors, including p53 and the $\operatorname{Cdc} 25$ phosphatase family. Phosphorylation of Cdc25 (leading to inactivation and nuclear export) and p53, with subsequent transcriptional induction of downstream targets p $21^{\text {Cip } 1}$ and GADD $45 \alpha$, leads to a block of $\mathrm{Cdc} 2$-cyclin $\mathrm{B}$ and $\mathrm{G}_{2} / \mathrm{M}$ cell cycle arrest. These events prevent podocyte mitosis, and therefore limit proliferation [24].

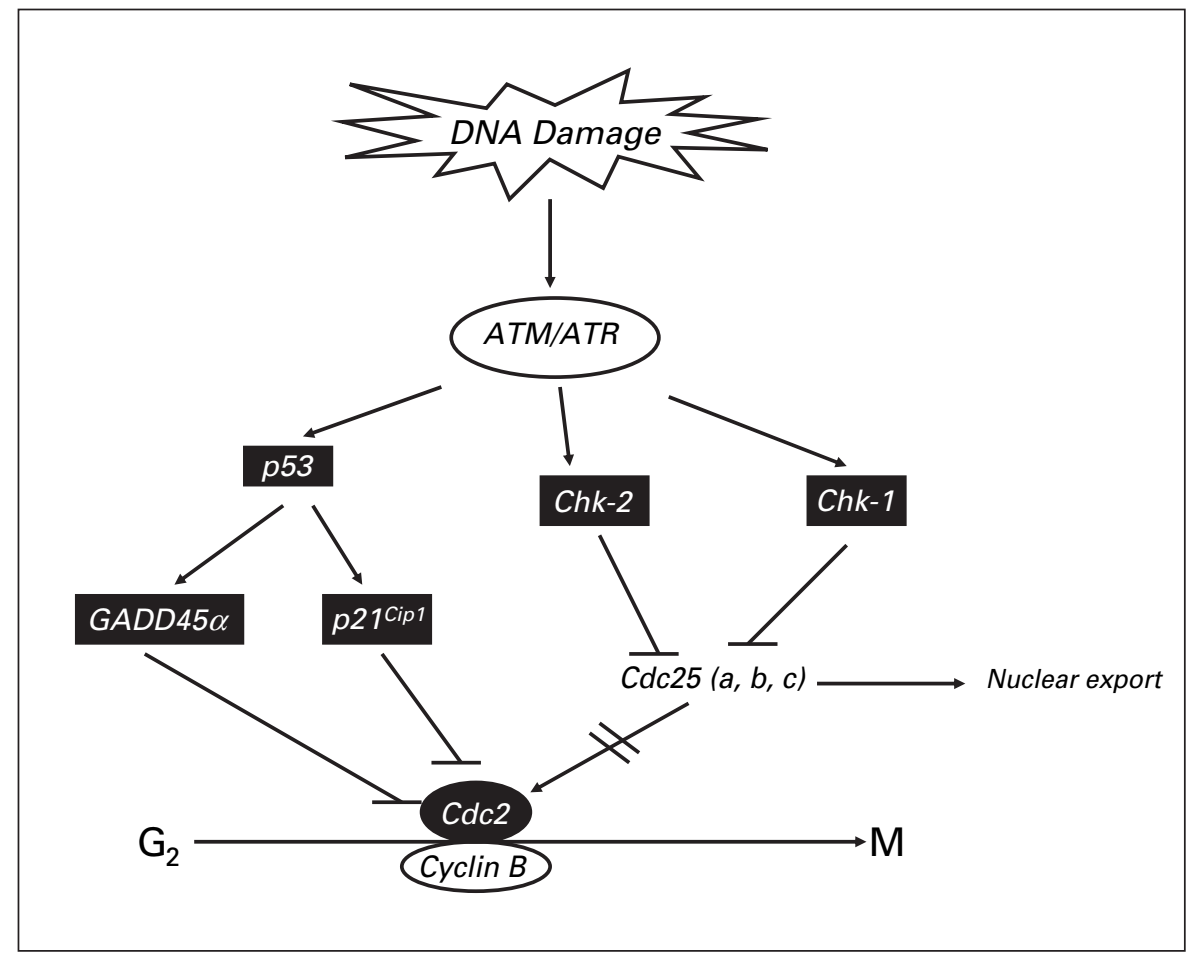

Recently, Milovanceva-Popovska et al. [25] examined the role of roscovitine in PHN. Treatment with roscovitine caused a statistically significant reduction in glomerular mitotic figures, bromodeoxyuridine-positive cells, and PCNA-positive cells. In addition, cyclin D1 decreased in the roscovitine group. This further supports that even in podocyte-injury models that have conventionally been considered non-proliferative, in response to injury, the cells may re-engage the cell cycle but are unable to successfully undergo mitosis/cytokinesis. It is currently unclear whether blocking the pro-proliferative cell cycle regulatory proteins in a non-proliferative disease model will prove beneficial in reducing progressive renal deterioration.

\section{Podocyte Hypertrophy}

Recent studies have shown that podocytes also undergo hypertrophy following injury, which may be the podocyte's attempt to cover denuded areas of glomerular basement membrane following the loss of neighboring cells [18]. A final common pathway to progressive glomerular scarring is increased intraglomerular capillary pressure, which results in increased mechanical stretch on resident glomerular cells. Applying mechanical stretch to cultured mesangial cells activates a variety of pro-proliferative sig- naling pathways, resulting in proliferation [26]. In contrast, mechanical stretch decreases podocyte proliferation [27]. Recent studies in cultured podocytes show that mechanical stretch decreases cyclins D1, A, and B1, and $\mathrm{Cdc} 2$, and increases CDK-inhibitors p $21^{\text {Cip } 1}$ and p $27^{\text {Kip } 1}$ [27]. Interestingly, exposing cultured mouse podocytes to cyclic mechanical stretch also induces a hypertrophic phenotype in podocytes [28]. The mechanisms may be due to $\mathrm{p} 21^{\mathrm{Cip} 1}$. In contrast to the growth arrest and hypertrophy induced in wild-type cells exposed to stretch, p $21^{\text {Cip } 1-/-~ p o d o c y t e s ~ c o n t i n u e d ~ t o ~ p r o l i f e r a t e ~ a n d ~ d i d ~ n o t ~}$ hypertrophy. Thus, mechanical stretch inhibits podocyte proliferation and prompts the cell to adopt a hypertrophic phenotype, both events regulated by the CDK-inhibitor p2 ${ }^{\text {Cip1 }}$ [28].

Diabetic nephropathy is characterized by glomerular hypertrophy. Upon study of Zucker diabetic fatty rats (ZDF- $f a / f a$ ), a model of type 2 diabetes, Hoshi et al. [29] found that tissue from diabetic rats, by morphometric analysis, had significantly increased glomerular volume and sclerosis. This was associated with increased expression of $\mathrm{p} 27^{\mathrm{Kip} 1}$, predominantly localized to podocytes, and $\mathrm{p} 21^{\mathrm{Cip} 1}$, but unchanged levels of $\mathrm{p} 57^{\mathrm{Kip} 2}$. An in vitro correlate confirmed that podocytes exposed to hyperglycemia exhibited cell hypertrophy, with accompanying in- 
creased levels of $\mathrm{p} 27^{\mathrm{Kip} 1}$, but unchanged levels of $\mathrm{p} 21^{\mathrm{Cip} 1}$ and $\mathrm{p} 57^{\mathrm{Kip} 2}$. This study demonstrated that CDK-inhibitors may underlie the podocyte's tendency to undergo hypertrophy in states of hyperglycemia. Thus, in many injury models, although podocyte hypertrophy is initially compensatory in response to podocyte loss, this response is likely maladaptive and contributes to the development of glomerulosclerosis [29].

\section{Podocyte Apoptosis}

As the reduction in podocyte number is closely associated with the development of glomerulosclerosis, the biological significance of apoptosis in podocyte depletion has recently been examined. In wild-type podocytes, upon exposure to TGF- $\beta_{1}$, a cytokine important in glomerular disease induction and progression, Takehiko Wada et al. found that $\mathrm{p} 21^{\mathrm{Cip} 1}$ levels were increased, which was associated with an increase in podocyte apoptosis. To examine further the role of $\mathrm{p} 21^{\text {Cip } 1}$ in podocyte apoptosis,

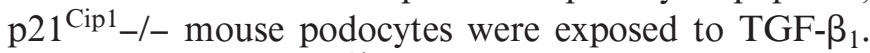
Interestingly, in $\mathrm{p} 21^{\mathrm{Cip} 1}-/-$ podocytes, no significant apoptosis was seen when compared to $\mathrm{p} 21^{\mathrm{Cip} 1}+/+$ cells. This finding was associated with an increase in anti-apoptotic Bcl-2 in $\mathrm{p} 21^{\mathrm{Cip} 1}-/$ - podocytes, a finding not observed in $\mathrm{p} 21^{\mathrm{Cip} 1}+/+$. Restoration of $\mathrm{p} 21^{\mathrm{Cip} 1}$ by an adenoviral transfection prevented the TGF- $\beta_{1}$-induced increase in Bcl-2 expression, resulting in increased apoptosis. These findings suggest that the upregulation of anti-apoptotic Bcl-2 is suppressed in the presence of the CDK-inhibitor $\mathrm{p} 21^{\mathrm{Cip} 1}$ under disease conditions, supporting a critical role for $\mathrm{p} 21^{\mathrm{Cip} 1}$ in triggering apoptosis in response to injury [pers. commun.].

\section{Novel Cell Cycle Proteins and Podocytes: CDK5}

Recently, CDK5, a non-classical and novel CDK that increases in certain post-mitotic cells, with highest levels observed in the brain, has been shown to increase in podo- cytes during differentiation in culture and in developing fetal kidneys. CDK5 declines in experimental diseases associated with podocyte de-differentiation and proliferation, including anti-glomerular antibody disease and HIVassociated nephropathy, implicating a role for CDK5 in maintaining the mature podocyte phenotype. Indeed, in vitro, inhibiting CDK5 activity, pharmacologically and with small interfering RNA, significantly altered podocyte shape, with a dramatic reorganization of the actin cytoskeleton. CDK5 inhibition had no effect on proliferation. Accordingly, a paradigm is developing that CDK5 is involved in maintaining the podocyte's complex morphology, critical for its highly specialized function [30].

\section{Conclusion}

A brief overview of the extensive body of literature supporting a critical role for cell cycle regulatory proteins in diseases of the glomerulus has been provided (table 1). The late changes of increased extracellular matrix and progressive glomerulosclerosis are preceded by, and closely linked to, the various fates that a cell can follow in response to injury including proliferation, apoptosis, hypertrophy, and senescence, all of which are regulated at the level of the cell cycle. The expectation is that attempts to understand the role of the cell cycle in the pathophysiology of glomerular diseases ultimately will lead to the development of novel therapeutic approaches to preserve renal function.

\section{Acknowledgements}

This work was supported by National Institute of Health grants to S.J.S. (DK60525, DK56799, DK51096), and by the American Diabetes Association. S.J.S. is also an Established Investigator of the American Heart Association.

\section{References}

1 Griffin S, Pichler R, Dittrich M, Durvasula R, Shankland S: Cell cycle control in glomerular disease. Springer Semin Immunopathol 2003; 24:441-457.

2 Shankland S, Wolf G: Cell cycle regulatory proteins in renal disease: role in hypertrophy, proliferation, and apoptosis. Am J Physiol Renal Physiol 2000;278:F515-F529.

-3 Couser W, Johnson R: Mechanisms of progressive renal disease in glomerulonephritis. Am J Kidney Dis 1994;23:193-198.

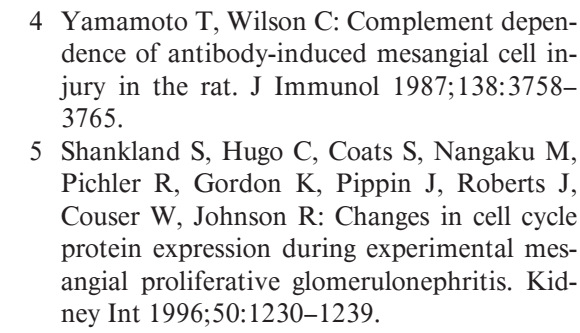

Yamamoto T, Wilson C: Complement dependence of antibody-induced mesangial cell injury in the rat. J Immunol 1987; 138:3758-

Pichler R, Gordon K, Pippin J, Roberts J, Couser W, Johnson R: Changes in cell cycle angial proliferative glomerulonephritis. Kidney Int 1996;50:1230-1239.

\footnotetext{
6 Pippin J, Qu Q, Meijer L, Shankland S: Direct in vivo inhibition of the nuclear cell cycle cascade in experimental mesangial proliferative glomerulonephritis with roscovitine, a novel cyclin-dependent kinase antagonist. J Clin Invest 1997;100:2512-2520.

-7 Hiromura K, Haseley L, Zhang P, Monkawa T, Durvasula R, Petermann A, Alpers C, Mundel P, Shankland S: Podocyte expression of CDK-inhibitor p57 during development and disease. Kidney Int 2001;60:2235-2246.
} 
8 Ophascharoensuk V, Fero M, Hughes J, Roberts J, Shankland S: The cyclin-dependent kinase inhibitor $\mathrm{p} 27^{\mathrm{Kip} 1}$ safeguards against inflammatory injury. Nat Med 1998;4:575-580.

$\checkmark 9$ Hiromura K, Pippin J, Fero M, Roberts J, Shankland S: Modulation of apoptosis by the cyclin-dependent kinase inhibitor p2 $7^{\mathrm{Kip} 1}$. J Clin Invest 1999; 103:597-604.

-10 Young B, Johnson R, Alpers C, Eng E, Gordon K, Floege J, Couser W, Seidel K: Cellular events in the evolution of experimental diabetic nephropathy. Kidney Int 1995;47:935944.

11 Feliers D, Frank M, Riley D: Activation of cyclin D1-CDK4 and CDK4-directed phosphorylation of RB protein in diabetic mesangial hypertrophy. Diabetes 2002;51:3290-3299.

-12 Fan Y, Weiss R: Exogenous attenuation of p21 decreases mesangial cell hypertrophy as a result of hyperglycemia and IGF-1. J Am Soc Nephrol 2004; 15:575-584.

13 Wolf G, Schroeder R, Zahner G, Stahl R, Shankland S: High glucose-induced hypertrophy of mesangial cells requires p27, an inhibitor of cyclin-dependent kinases. Am J Pathol 2001;158:1090-1100.

14 Monkawa T, Hiromura K, Wolf G, Shankland $\mathrm{S}$ : The hypertrophic effect of TGF- $\beta$ is decreased in the absence of cyclin-dependent kinase-inhibitors p21 and p27. J Am Soc Nephrol 2002;13:1172-1178.

15 Kuan C, Al-Douahji M, Shankland S: The cyclin kinase inhibitor p $21^{\text {Cip } 1 \text { Waf } 1}$ is increased in experimental diabetic nephropathy: potential role in glomerular hypertrophy. J Am Soc Nephrol 1998;9:986-993.
6 Al-Douahji M, Brugarolas J, Brown P, Stehman-Breen C, Alpers C, Shankland S: The cyclin kinase inhibitor $\mathrm{p} 21^{\mathrm{Cip} 1 / \text { Waf1 }}$ is required for glomerular hypertrophy in experimental diabetic nephropathy. Kidney Int 1999;56:16911699.

17 Awazu M, Omori S, Ishikura K, Hida M, Fujita $\mathrm{H}$ : The lack of cyclin kinase p2 $7^{\mathrm{Kip} 1}$ ameliorates progression of diabetic nephropathy. $\mathrm{J}$ Am Soc Nephrol 2003; 14:699-708.

18 Pavenstädt H, Kriz W, Kretzler M: Cell biology of the glomerular podocyte. Physiol Rev 2003;83:253-307.

19 Nagata M, Nakayama K, Terada Y, Hoshi S, Watanabe T: Cell cycle regulation and differentiation in the human podocyte lineage. Am J Kidney Dis 1998;153:1511-1520.

20 Barisoni L, Mokrzycki M, Sablay L, Nagata M, Yamase H, Mundel P: Podocyte cell cycle regulation and proliferation in collapsing glomerulonephritis. Kidney Int 2000;58:137-143.

21 Kim Y, Alpers C, Brugarolas J, Johnson R, Couser W, Shankland S: The cyclin kinase inhibitor p21 Cip1/Waf1 limits glomerular epithelial cell proliferation in experimental glomerulonephritis. Kidney Int 1999;55:2349-2361.

22 Couser W, Pippin J, Shankland S: Complement (C5b-9) induces DNA synthesis in rat mesangial cells in vitro. Kidney Int 2001;59: 905-912.

-23 Pippin J, Durvasula R, Petermann A, Hiromura K, Couser W, Shankland S: DNA damage is a novel response to sublytic C5b-9-induced injury in podocytes. J Clin Invest 2003; 111:877-885.

24 Eastman A: Cell cycle checkpoints and their impact on anti-cancer therapeutic strategies. J Cell Biochem 2004;91:223-231.
25 Milovanceva-Popovska M, Kunter U, Ostendorf T, Petermann A, Rong S, Eitner R, Kerjaschki D, Barnett A, Floege J: R-roscovitine (CYC202) alleviates renal cell proliferation in nephritis without aggravating podocyte injury. Kidney Int 2005;67:1362-1370.

26 Harris R, Haralson M, Badr K: Continuous stretch-relaxation in culture alters rat mesangial cell morphology, growth characteristics, and metabolic activity. Biochem J 1992;313: 697-710.

27 Petermann A, Hiromura K, Blonski M, Pippin J, Monkawa T, Durvasula R, Couser W, Shankland S: Mechanical stress reduces podocyte proliferation in vitro. Kidney Int 2002;61:4050.

28 Petermann A, Pippin J, Durvasula R, Pichler R, Hiromura K, Monkawa T, Couser W, Shankland S: Mechanical stretch induces podocyte hypertrophy in vitro. Kidney Int 2005;67:157-166.

29 Hoshi S, Shu Y, Yoshida F, Inagaki T, Sonoda J, Watanabe T, Nomoto K, Nagata M: Podocyte injury promotes progressive nephropathy in Zucker diabetic fatty rats. Lab Invest 2002; $82: 25-35$.

30 Griffin S, Hiromura K, Pippin J, Petermann A, Blonski M, Krofft R, Takahashi S, Kulkarnc A, Shankland S: Cyclin-dependent kinase-5 is a regulator of podocyte differentiation, proliferation, and morphology. Am J Pathol 2004; 165:1175-1185.

An unabridged list of references is available from the authors upon request. 